Tropical Journal of Pharmaceutical Research April 2021; 20 (4): 849-858

ISSN: $1596-5996$ (print); 1596-9827 (electronic)

(C) Pharmacotherapy Group, Faculty of Pharmacy, University of Benin, Benin City, 300001 Nigeria.

Original Research Article

http://dx.doi.org/10.4314/tjpr.v20i4.27

\title{
Antimycobacterial activity of aqueous and methanol extracts of nine plants against Mycobacterium bacteria
}

\author{
Alveera Singh ${ }^{1}$, Katharigatta N. Venugopala ${ }^{1,2^{*}}$, Melendran Pillay ${ }^{3}$, Francis \\ Shode ${ }^{1}$, Yacoob Coovadia ${ }^{2}$ and Bharti Odhav ${ }^{1^{*}}$ \\ ${ }^{1}$ Department of Biotechnology and Food Technology, Durban University of Technology, Durban 4001, South Africa, \\ ${ }^{2}$ Department of Pharmaceutical Sciences, College of Clinical Pharmacy, King Faisal University, Al-Ahsa 31982, Saudi Arabia, \\ ${ }^{3}$ Department of Microbiology, NHLS, Inkosi Albert Luthuli Hospital, South Africa
}

*For correspondence: Email: katharigattav@dut.ac.za; Tel: +27-31-373-6887, Fax: +27-86-674-1004

\begin{abstract}
Purpose: The present study was done to evaluate the antimycobacterial activity of aqueous and methanol extracts of nine plants viz., Buddleja saligna, Carpobrotus dimidiatus, Capparis tomentosa, Dichrostachys cinerea, Ekebergia capensis, Ficus sur, Gunnera perpensa, Leonotis leonurus and Tetradenia riparia in South Africa.

Methods: Aqueous and methanol extracts of the leaves the plants were tested in vitro for their activity against Mycobacterium smegmatis, Mycobacterium tuberculosis H37RV (ATCC 25177) and three well-characterized clinical isolates of MDR and XDR-TB isolates using the agar incorporation method. The minimum inhibitory concentration (MIC) of each of the active plant extract was determined using the broth microdilution method. Cytotoxic effect was evaluated against the mouse BALB/C monocyte macrophage (J774.2) and peripheral blood mononuclear cells (PBMCS) whole the toxicity screening was done using the brine shrimp lethality assay. Composition of each of the plants was determined using thin layer chromatography while qualitative analysis of antimycobacterial compounds was done using TLC-Bioautography

Results: The methanol extracts of B. saligna, C. tormentosa and C. dimidiatus; and aqueous extracts of G. perpensa and T. riparia possessed significant activity against M. smegmatis, M. tuberculosis H37Rv (ATCC 25177) and the three well-characterized clinical isolates of MDR and XDR-TB. Except for a high concentration of $\mathrm{G}$. perpensa none of the other plants which possessed antimycobacterial activity showed any toxic or cytotoxic activity.

Conclusion: Our findings show that B. saligna, C. tormentosa, C. dimidiatus, G. perpensa, and T. riparia have antimycobacterial activity. Further studies would aim at isolation and identification of the active compounds from the plants extracts which had positive antimycobacterial activity.

Keywords: Anti-TB activity, extraction, Safety Evaluation, MDR-strains, XDR-strains
\end{abstract}

\begin{abstract}
This is an Open Access article that uses a fund-ing model which does not charge readers or their institutions for access and distributed under the terms of the Creative Commons Attribution License (http://creativecommons.org/licenses/by/4.0) and the Budapest Open Access Initiative (http://www.budapestopenaccessinitiative.org/read), which permit unrestricted use, distribution, and reproduction in any medium, provided the original work is properly credited.

Tropical Journal of Pharmaceutical Research is indexed by Science Citation Index (SciSearch), Scopus, International Pharmaceutical Abstract, Chemical Abstracts, Embase, Index Copernicus, EBSCO, African Index Medicus, JournalSeek, Journal Citation Reports/Science Edition, Directory of Open Access Journals (DOAJ), African Journal Online, Bioline International, Open-J-Gate and Pharmacy Abstracts
\end{abstract}

\section{INTRODUCTION}

Mycobacterium tuberculosis is the etiologic agent of tuberculosis (TB) in humans which infects about one-third of the world's population [1].
Despite more than forty years of antimycobacterial chemotherapy, TB remains one of the leading infectious disease killers worldwide. As at 2015, there were an estimated 10.4 million new cases of TB disease worldwide 
and this included 1.2 million human immunodeficiency virus (HIV), positive people. The association with the HIV, increasing emergence of multi-drug resistant TB (MDR-TB) and extensively drug-resistant TB (XDR-TB) have made the TB situation worse and posed a serious health threat [2]. The current TB chemotherapy is too long and many drug combinations have to be taken for 6 to 9 months and this has been identified as an important cofactor in the increasing rate of drug resistant-TB, MDR and XDR-TB development [3]. This increase in resistance to conventional antibiotics by microorganisms has compelled the search for new, efficient and cost effective ways for the control of infectious diseases [4, 5].

Natural sources provide numerous examples of interesting secondary metabolites with antimycobacterial activity, indicating that natural products could be rewarding in the discovery of new antimycobacterial leads [6]. Medicinal plants offer a great hope to fulfill these needs and have been used for curing diseases for many centuries. These have been used extensively either as pure compounds or crude materials [7]. As herbal medicine forms a significant part of culture and tradition of rural people in developing countries, there is an increasing trend to integrate traditional medicine into primary health care [8]. Furthermore, many orthodox medicines are expensive or inaccessible making it very necessary to validate the efficacy and safety of plant sources of medicines.

Plant-derived antimycobacterial compounds belong to an exceptionally wide diversity of classes, including terpenoids, alkaloids, peptides, phenolics and coumarins. These medicinal plants remain an important resource to find new therapeutic agents [9] and the advantages of using these compounds includes fewer side effects, better patient acceptance due to long history of use, reduced costs and cultivability rendering them renewable in nature [10]. A number of South African plants have been shown to contain antimycobacterial activities [11-13]. This leads us to identification and collection of specimens of medicinal plant species found in South Africa, namely Buddleja saligna, Carpobrotus dimidiatus, Capparis tomentosa, Dichrostachys cinerea, Ekebergia capensis, Ficus sur, Gunnera perpensa, Leonotis leonurus and Tetradenia riparia. The selection of these plants is based on reports in literature from their use in traditional medicine to treat various ailments including bronchitis, cough, diarrhea, fever, and even tuberculosis (Table 1) [13-17].
Table 1: Documented use of plants that treat TBrelated ailments

\begin{tabular}{ll}
\hline Plant & Documented Use \\
\hline B. saligna & TB Symptoms [3] \\
C. tormentosa & Chronic cough and chest pain [17] \\
C. dimidiatus & TB, Infections [15] \\
D. cinerea & Leprosy and coughs [16] \\
E. capensis & Chronic cough, respiratory chest \\
& complaints and TB [13] \\
F. sur & TB [18] \\
G. perpensa & TB Symptoms [13] \\
L. leonurus & Cough and respiratory ailments \\
T. riparia & [14] \\
& TB Symptoms, cough and \\
& respiratory ailments [14] \\
\hline
\end{tabular}

The aim of this study was to evaluate some plant species currently used in for treatment of TB and other respiratory diseases for their antimycobacterial activity. Cytotoxicity of active plant extracts towards mouse BALB/C monocyte macrophage (J774.2) and peripheral blood mononuclear cells (PBMCs) and toxicity against brine shrimp were also performed.

\section{EXPERIMENTAL}

\section{MATERIALS AND METHODS}

\section{Collection of Plants}

The leaves of Buddleja saligna, Capparis tomentosa, Carpobrotus dimidiatus, Dichrostachys cinerea, Ekebergia capensis, Ficus sur, Gunnera perpensa, Leonotis leonurus and Tetradenia riparia were authenticated and supplied by Prof $\mathrm{H}$. Baijnath of the University of KwaZulu-Natal, Westville Campus, Durban, South Africa and the specimen's voucher was deposited in the Ward Herbarium of the University. They 5were separated and washed several times with distilled water until no foreign material remained and air dried for $24 \mathrm{~h}$. Thereafter, they were dried in an oven (Memmert, South Africa) at $25^{\circ} \mathrm{C}$ for 7 days. The dried leaves were powdered using an industrial grinder (Retsch Gmbh, West Germany) and stored in Schott bottles in the dark room until required for extraction.

\section{Extraction}

\section{Aqueous extraction}

The powdered leaves $(20 \mathrm{~g})$ was boiled in distilled water and filtered by gravity using Whatman No. 1 filter paper. This was then concentrated by placing the filtrate in a bio freezer (Snijders Scientific, Holland) at $-70{ }^{\circ} \mathrm{C}$ and lyophilized (Virtis Benchtop Freeze Dryer). The lyophilized material was used as a stock and 
working solutions were prepared for appropriate applications.

\section{Methanol extraction}

Dried leaves were extracted with methanol, filtered and the filtrate was concentrated using a Buchi RE Rotoevaporator at $50{ }^{\circ} \mathrm{C}$. The concentrate was placed in a bio freezer and lyophilized using a Virtis Benchtop Freeze Dryer. Aliquots were prepared from the dried crude extract and dissolved in solvents depending on the experimental protocol.

\section{Antimycobacterial Activity of the Plant Extracts}

\section{Mycobacterial strains and isolates}

Reference drug susceptible strain $M$. tuberculosis (ATCC 25177) as control, well characterized clinical isolates of MDR and XDR$\mathrm{TB}$; and fast growing $M$. smegmatis were obtained from the Department of Microbiology, NHLS laboratory based at the Inkosi Albert Luthuli Hospital in Durban, South Africa. The purity of the mycobacterial strains was checked by Ziehl-Neelsen staining before used in the antimycobacterial assays. Susceptibility profile of the clinical isolates against standard antituberculosis drugs was as follows: MDR-TB resistant to RIF (Rifampicin) and INH (Isoniazid); XDR-TB resistant to RIF, INH, KAN (Kanamycin) and OFLX (Ofloxacin).

\section{Preliminary Sensitivity Test}

Plant extract (100 mg) was dissolved in $1 \mathrm{~mL}$ of distilled water and $1 \mathrm{~mL}$ of each of the plant extracts was introduced in $100 \mathrm{~mL}$ of prepared molten Middlebrook 7H11 agar base containing Middlebrook 7H9 (FlukaM0178) broth containing glycerol (Fluka 49769) and Middlebrook Oleic Albumin Dextrose Catalase (OADC) growth supplement (Fluka M0553) in a bottle, mixed and aseptically poured into Petri dish and allowed to gel. The plates were then ready for inoculation of M. smegmatis and M. tuberculosis H37Rv (ATCC 25177). M. smegmatis was aseptically inoculated into Middlebrook $7 \mathrm{H} 11$ agar base containing glycerol (Fluka 49769) and Middlebrook Oleic Albumin Dextrose Catalase (OADC) growth supplement (Fluka M0553); and incubated at $37^{\circ} \mathrm{C}$ at 72 h. M. tuberculosis H37Rv (ATCC 25177), well characterized clinical isolates of MDR and XDR-TB was aseptically inoculated into Middlebrook $7 \mathrm{H} 11$ agar base containing glycerol (Fluka 49769) and Middlebrook Oleic Albumin Dextrose Catalase (OADC) growth supplement (Fluka M0553), sealed and incubated at $37^{\circ} \mathrm{C}$ for 21 days.

\section{Broth Microdilution Assay}

The two-fold microdilution method was used with minor modifications to determine the MIC values of the active plant extracts against $M$. smegmatis and M. tuberculosis H37Rv (ATCC 25177) in sterile flat-bottomed 96 well microtiter plates [19]. Bacterial inoculums were prepared from five days old grown cultures in Middlebrook $7 \mathrm{H} 9$ broth base containing Middlebrook $7 \mathrm{H} 9$ (FlukaM0178) broth containing glycerol (Fluka 49769) and Middlebrook oleic albumin dextrose catalase (OADC) growth supplement (Fluka M0553) and the turbidity was adjusted to the equivalent of McFarland No 1 ( $\left.3 \times 10^{8} \mathrm{CFU} / \mathrm{mL}\right)$. Each plant extract $(100 \mu \mathrm{L}$ of $2 \mathrm{mg} / \mathrm{mL})$ was serially diluted two folds with a broth base containing glycerol (Fluka 49769) and OADC growth supplement and $100 \mu \mathrm{L}$ was placed into a well in a microtiter plate. This was followed by the separate inoculation of $100 \mu \mathrm{L}$ of mycobacterial cultures into each well to complete a two-fold broth microdilution. Wells (6) with culture medium without the extract were used as negative control while wells (6) with inoculums and rifampicin or isoniazid were used as positive control. Each of the inoculated microtiter plate containing $M$. smegmatis was incubated at $37^{\circ} \mathrm{C}$ for $24 \mathrm{~h}$. To determine the minimum inhibitory concentration (MIC) values of the active plant extracts for $M$. smegmatis, $50 \mu \mathrm{L}(0.2 \mathrm{mg} / \mathrm{mL})$ iodonitrotetrazolium (INT) chloride salt was added to each well and plates incubated at $37^{\circ} \mathrm{C}$ for $24 \mathrm{~h}$. Bacterial growth in the wells was indicated by a change in color, whereas clear wells indicated inhibition by the extracts or positive control. The inoculated microtiter plates containing M. tuberculosis H37Rv (ATCC 25177) were incubated at $37^{\circ} \mathrm{C}$ for 5 days. To determine the MIC values of the active plant extracts against $M$. tuberculosis H37Rv (ATCC 25177), MDR-TB and XDR-TB; $50 \mu \mathrm{L}(1 \mathrm{mg} / \mathrm{mL})$ of freshly prepared reagent mixture 7 -hydroxy-3Hphenoxazin-3-one-10-oxide sodium salt (Resazurin) was added to each well and plates re-incubated at $37{ }^{\circ} \mathrm{C}$ for $24 \mathrm{~h}$. A color change from blue to pink indicated growth and the minimum inhibitory concentration (MIC) was interpreted as the lowest extract concentration which prevented the color change from blue to pink.

\section{Safety evaluation of the active plant extracts}

\section{Brine Shrimp Lethality Assay}

Brine shrimp lethality test (BST) was used to predict the presence of evaluate toxicity of the 
plant extracts as previously described [20]. Filtered, artificial seawater was prepared by dissolving $38 \mathrm{~g}$ of sea salt in $1 \mathrm{~L}$ of distilled water for hatching the shrimp eggs. The seawater was put in a small plastic container (hatching chamber) with a partition for dark (covered) and light areas and the shrimp eggs obtained from Natures Petland in Durban (South Africa) were added to the dark side of the chamber while the lamp above the other side (light) provided attraction for the hatched shrimp. Two days were allowed for the shrimp to hatch and mature as nauplii (larvae).

Solutions of the active plant extracts $(0.05,0.1$ and $1 \mathrm{mg} / \mathrm{mL}$ ) were made in distilled water and incubated in triplicate vials with the brine shrimp larvae. The volume was then adjusted to $5 \mathrm{~mL}$ with artificial sea water. Ten brine shrimp larvae were then placed in each of the triplicate vials and the remaining brine shrimp larvae were placed in artificial sea water to serve as a negative control. DEET, an organophosphate, was used as a positive control. After $24 \mathrm{~h}$ the nauplii were examined against a lighted background, with a magnifying glass and the average number of survived larvae was determined. Percentage mortality ( $\% \mathrm{M})$ was also calculated by dividing the number of dead nauplii by the total number and then multiplied by 100 $\%$. This served to ensure that the mortality of the nauplii was attributed to the bioactive compounds present in the plant extracts.

\section{Cytotoxic evaluation}

Cell lines and culture conditions: Mouse $B A L B / C$ monocyte macrophage (line J774.2) cell lines were maintained in DMEM media supplemented with $10 \%$ fetal calf serum, 100 $\mathrm{IU} / \mathrm{mL}$ penicillin, and $100 \mathrm{lg} / \mathrm{mL}$ streptomycin. Cells were maintained in a humidified atmosphere of $5 \% \mathrm{CO}_{2}$ at $37^{\circ} \mathrm{C}$ in an incubator.

Isolation of monocytes from whole blood: The collection, separation and isolation of peripheral blood mononuclear cells (PBMCs) was based on the modified methods described by Boyum [21]. All procedures were carried out under aseptic conditions. Buffy coat sample $(50 \mathrm{~mL})$ obtained from the South African National Blood Services was diluted with an equal volume of prewarmed Hanks' balanced salts solution (HBSS) (Bioscience, Durban, South Africa). This mixture was carefully layered onto prewarmed Histopaque 1077 (Sigma, Durban, South Africa) in a ratio of $5: 4$ in a sterile $15 \mathrm{~mL}$ centrifuge tubes. The tubes were transferred to a Beckman centrifuge and spun at room temperature at $2000 \mathrm{rpm}$ for $30 \mathrm{~min}$. Using a sterile Pasteur pipette, the mononuclear cells were carefully aspirated from the interface between the HBSS and the Histopaque and transferred to a sterile centrifuge tube. Mononuclear cells were washed twice in HBSS and centrifuged each time for $15 \mathrm{~min}$ at $1200 \mathrm{rpm}$ in room temperature to remove any residual Histopaque. The cell pellets were resuspended in one $m L$ RPMI 1640 (Bioscience) supplemented with $2 \mathrm{mM}$ - glutamine and $10 \%$ unheated fetal calf serum and $100 \mathrm{IU} / \mathrm{mL}$ penicillin and 100 $\mathrm{Ig} / \mathrm{mL}$ streptomycin.

Cell viability was determined using the trypan blue dye exclusion method [22]

MTT assay: Cytotoxicity of the active plant extracts on mouse BALB/C monocyte macrophage (J774.2) and peripheral blood mononuclear cells (PBMCs) was measured using microculture tetrazolium (MTT) assay [23]. Prior to use in the assay, the cells were grown to $80 \%$ confluence and synchronized by incubation in the assay media for $4 \mathrm{~h}$. The cells (10 000 cells/well) were then incubated with the active plant extract solutions $(0.05,0.1$ and $1 \mathrm{mg} / \mathrm{mL})$ for $48 \mathrm{~h}$. Aliquot $(10 \mu \mathrm{L}$ of a $5 \mathrm{mg} / \mathrm{mL})$ of MTT 3-(4,5dimethylthiazol-2-yl)-2,5-diphenyltetrazolium

bromide (Molecular probes, life technologies) solution was then added to each well and microtiter plates were incubated for $4 \mathrm{~h}$ at $37^{\circ} \mathrm{C}$ in a humidified incubator with $5 \% \mathrm{CO}_{2}$. Thereafter the media were removed and an aliquot of $100 \mu \mathrm{L}$ of DMSO was then added to the wells to dissolve the formazan crystals that formed in metabolically active cells and incubated for another hour. The plates were read at $595 \mathrm{~nm}$ on a plate reader (Digital Analogue Systems, Italy) and the data was analyzed by using the Microsoft Excel. The percentage growth inhibition was determined by using the following equation:

\section{$\%$ growth inhibition $=$}

$$
\frac{\text { Absorbance of treated cells }}{\text { Absorbancr of negrative control }} \times 100
$$

\section{Thin layer chromatography of the active plant extracts}

All organic solvents used were of HPLC grade. Methanol, hexane, and ethyl acetate were purchased from Merck (South Africa). Vanillin was purchased from Sigma-Aldrich (South Africa). A $5 \mu \mathrm{L}$ aliquot of each plant extract (1 $\mathrm{mg} / \mathrm{ml}$ in methanol) was loaded on Merck TLC F254/Silica gel 60 plates that were developed using the hexane: ethyl acetate eluent system at ratios of 7: $3(\mathrm{v} / \mathrm{v})$. The separated compounds were visualized using UV light at $254 \mathrm{~nm}$ and $366 \mathrm{~nm}$ (Camag Universal UV lamp TL-600) and 
by spraying the TLC plates with vanillin-sulphuric acid spray reagent $\left(15 \mathrm{~g}\right.$ vanillin in $1 \% \mathrm{H}_{2} \mathrm{SO}_{4}$ in methanol) and placing them in an oven at $100{ }^{\circ} \mathrm{C}$ until the separation of the bands could be visualized $[24,25]$.

\section{TLC-Bioautography}

The bacterial species was grown and maintained in Middlebrooks $7 \mathrm{H} 9$ (Sigma) broth containing glycerol (Sigma) and Middlebrooks Oleic Albumin Dextrose Catalase (OADC) growth supplement (Sigma). Before analysis, test culture was grown for 3 days in a shaking incubator at $37^{\circ} \mathrm{C}$, then centrifuged at $2400 \mathrm{rpm}$ for $10 \mathrm{~min}$ and the supernatant was discarded. Fresh medium was then added and vortexed at a high speed. A McFarland No 1 standard was measured at 600 $\mathrm{nm}$ using a UV-Vis spectrophotometer (Biochrom). The purity of the cultures was checked by means of the Ziehl-Neelsen stain before use in bioautography.

The qualitative antibacterial activity was carried out according to a procedure outlined by Begue and Kline [26]. For bioautographic analysis, $2 \mu \mathrm{L}$ of each extract was loaded on the TLC plates and developed in mobile phase hexane: ethyl acetate 7:3 (v/v). The chromatograms were dried at room temperature in a dark cupboard for 2 days to remove the solvents, sprayed with an overnight culture of $M$. smegmatis until completely wet and incubated at $37^{\circ} \mathrm{C}$ in a humidified chamber for $24 \mathrm{~h}$. The plates were sprayed with $\rho$-iodonitrotetrazolium violet (INT) (Sigma, South Afrcia) and incubated for a further $24 \mathrm{~h}$ and the presence of clear bands on the plates against a purple background indicated growth inhibition.

\section{RESULTS}

\section{Antimycobacterial Screening of the Nine Plants}

During our screening, only the aqueous extracts of $G$. perpensa and $T$. riparia; and methanol extracts of $B$. saligna, $C$. tormentosa and $C$. dimidiatus showed activity against $M$. smegmatis and M. tuberculosis H37Rv ATCC 25177 (Table $2)$. These plant extracts were the ones selected for further antimycobacterial study against three well-characterized clinical isolates of MDR-TB and three well-characterized clinical isolates of XDR-TB. MDR-TB resistant to at least rifampicin and isoniazid [27]. The MIC of the active plant extracts are shown in Table 3.

The mean MIC results of the aqueous and methanol crude extracts of each of the active plants showed significantly lower antimycobacterial activities against $M$. smegmatis and M. tuberculosis H37Rv ATCC 25177 in comparison to the positive controls (rifampicin and isoniazid). Our study showed that the extracts of $D$. cinerea, E. capensis, F. sur and L. leonurus, (earlier reported to be used in the treatment of TB and related diseases [13, 16, 18]) did not have any activity against the screened strains in our assays.

\section{Safety Analysis of the Active Plant Extracts}

\section{Toxicity}

Other than the I $\mathrm{mg} / \mathrm{ml}$ extract of $G$. perpensa, the extracts of $B$. saligna, $C$. tormentosa, $C$. dimidiatus and $T$. riparia had average cell death of brine shrimp larvae of less than $20 \%$ (much lower than the shrimp death $\geq 50 \%$ for a compound to be considered toxic) (Figure 1) unlike the positive control, DEET, a well-known organophosphate with mortality of $100 \%$.

\section{Cytotoxicity}

The cytotoxic effects of the five active plants extract namely $B$. saligna, $C$. tormentosa, $C$. dimidiatus, $G$. perpensa and $T$. riparia against mouse BALB/C monocyte macrophage (J774.2) and human peripheral blood mononuclear cells (PBMCs) is shown in Figure 2 and Figure 3 respectively. It was observed that the plant extracts stimulated the growth of the cells and was not toxic to the J774.2 cell line at the highest concentration tested. After $48 \mathrm{~h}$ the methanol extracts of $B$. saligna, $C$. tormentosa, $C$. dimidiatus and aqueous extracts of $T$. riparia showed an increase in cell viability for the PBMCs (Figure 3) unlike the aqueous extract of $G$. perpensa which showed a decrease in cell viability as the concentration of the plant extract increased. The highest concentration of 1.000 $\mathrm{mg} / \mathrm{mL}$ showed toxic activity to the PBMC's where there was only $25.26 \pm 9.96 \%$ cell viability.

\section{Chromatographic Analysis of the Active Plants Extracts}

Using different solvents in TLC, the mobile phase that gave the best separation was hexane:ethyl acetate (7:3) sprayed with vanillin-sulphuric spray reagent as shown in Figure 4. Three to four distinct band could be seen for $B$. saligna, $C$. tormentosa and $C$. dimidiatus; and aqueous leaf extracts of $G$. perpensa and $T$. riparia. 
Table 2: Antimycobacterial activity some plant extracts

\begin{tabular}{|c|c|c|c|c|c|c|}
\hline Plant & $\begin{array}{l}\text { Part } \\
\text { Used }\end{array}$ & $\begin{array}{l}\text { Extract (1 } \\
\mathrm{mg} / \mathrm{mL})\end{array}$ & M. smegmatis & $\begin{array}{c}\text { M. tuberculo- } \\
\text { sis H37Rv }\end{array}$ & $\begin{array}{l}\text { Clinical } \\
\text { Isolate } \\
\text { MDR-TB } \\
\end{array}$ & $\begin{array}{l}\text { Clinical } \\
\text { Isolate } \\
\text { XDR-TB }\end{array}$ \\
\hline B. saligna & Leaf & Aqueous & G & G & G & G \\
\hline B. saligna & Leaf & Methanol & NG & NG & NG & NG \\
\hline C. tomentosa & Leaf & Aqueous & G & G & G & G \\
\hline C. tomentosa & Leaf & Methanol & NG & NG & NG & NG \\
\hline C. dimidiatus & Leaf & Aqueous & G & G & G & G \\
\hline C. dimidiatus & Leaf & Methanol & NG & NG & NG & NG \\
\hline D. cinerea & Leaf & Aqueous & G & G & G & G \\
\hline D. cinerea & Leaf & Methanol & G & G & G & G \\
\hline E. capensis & Leaf & Aqueous & G & G & G & $G$ \\
\hline E. capensis & Leaf & Methanol & G & G & G & G \\
\hline F. sur & Leaf & Aqueous & G & G & G & G \\
\hline F. sur & Leaf & Methanol & G & G & G & G \\
\hline G. perpensa & Leaf & Aqueous & NG & NG & NG & G \\
\hline G. perpensa & Leaf & Methanol & G & G & G & G \\
\hline L. leonurus & Leaf & Aqueous & G & G & G & G \\
\hline L. leonurus & Leaf & Methanol & G & G & G & G \\
\hline T. riparia & Leaf & Aqueous & NG & NG & NG & G \\
\hline T. riparia & Leaf & Methanol & G & G & G & G \\
\hline Rifampicin & & & NG & NG & G & G \\
\hline Isoniazid & & & NG & NG & G & G \\
\hline $\begin{array}{l}\text { Drug-Free } \\
\text { Control }\end{array}$ & & & G & G & G & G \\
\hline Distilled Water & 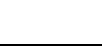 & & G & G & G & G \\
\hline
\end{tabular}

Table 3: Minimum inhibitory concentration (MIC) of some active plant extracts against $M$. smegmatis

\begin{tabular}{|c|c|c|c|c|c|}
\hline \multirow{2}{*}{ Plant } & \multirow{2}{*}{ Extract } & \multicolumn{4}{|c|}{$\mathrm{MIC}(\mathrm{mg} / \mathrm{mL})$} \\
\hline & & M. smegmatis & MTB H37Rv (25177) & $\begin{array}{c}\text { Clinical } \\
\text { Isolate MDR- } \\
\text { TB }\end{array}$ & $\begin{array}{c}\text { Clinical Isolate } \\
\text { XDR-TB }\end{array}$ \\
\hline B. saligna & Methanol & 0.125 & 0.125 & 0.125 & 0.125 \\
\hline C. tomentosa & Methanol & 0.500 & 0.500 & 1.000 & 1.000 \\
\hline C. dimidiatus & Methanol & 0.125 & 0.125 & 0.500 & 0.500 \\
\hline G. perpensa & Aqueous & 0.250 & 0.250 & 0.500 & - \\
\hline T. riparia & Aqueous & 0.125 & 0.250 & 0.250 & - \\
\hline Rifampicin & & 0.001 & 0.001 & - & - \\
\hline Isoniazid & & 0.003 & 0.003 & - & - \\
\hline
\end{tabular}




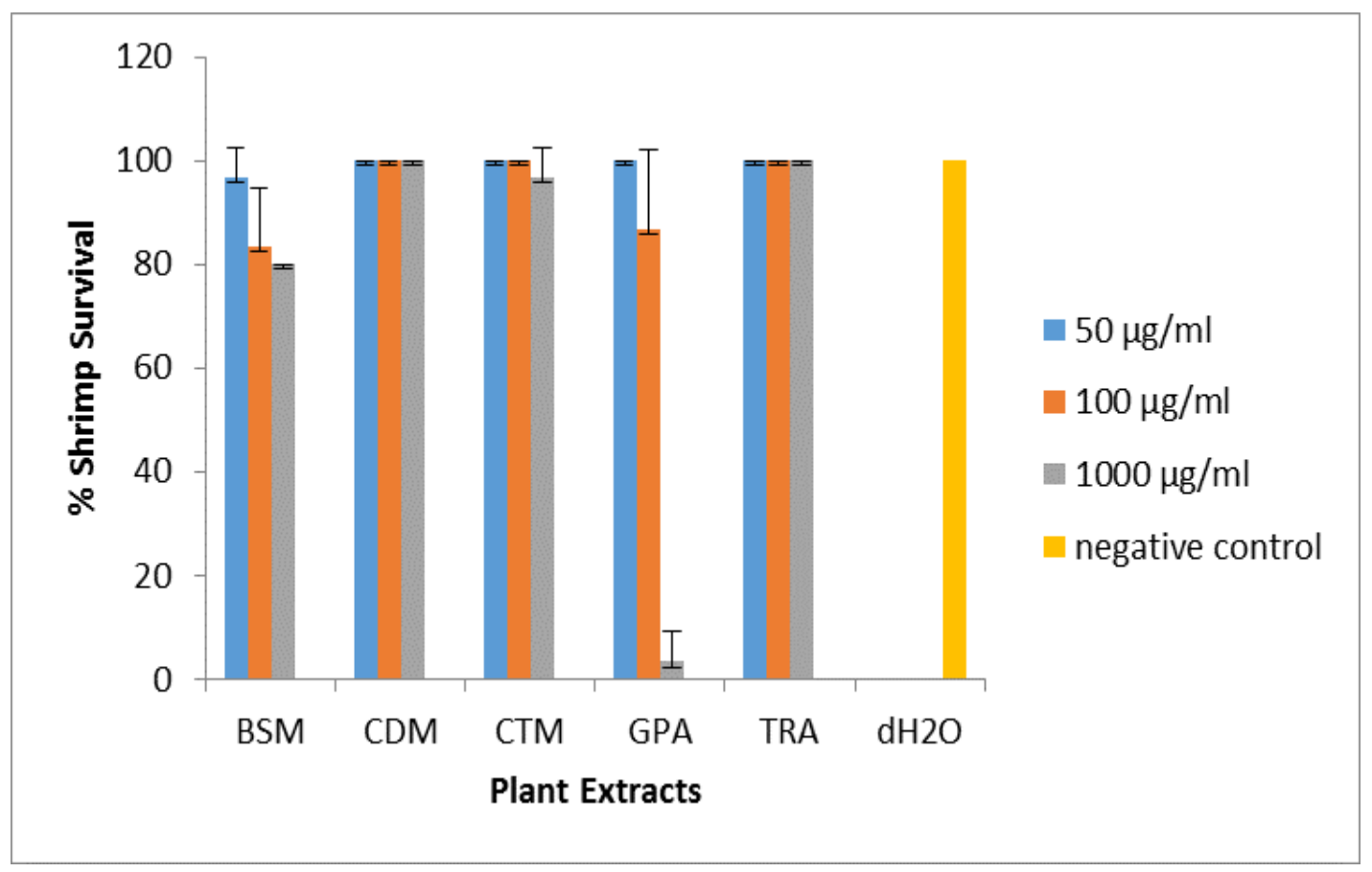

Figure 1: Brine shrimp larvicidal activity of the active plant extracts $B$. saligna (BSM), C. tormentosa (CTM, methanol extract), C. dimidiatus (CDM, methoanol extract), G. perpensa (GPA, aqueous extract) and T. riparia (TRA, aqueous extract) at different concentrations. Each column is represented as mean $\pm \operatorname{SD}(n=3)$.

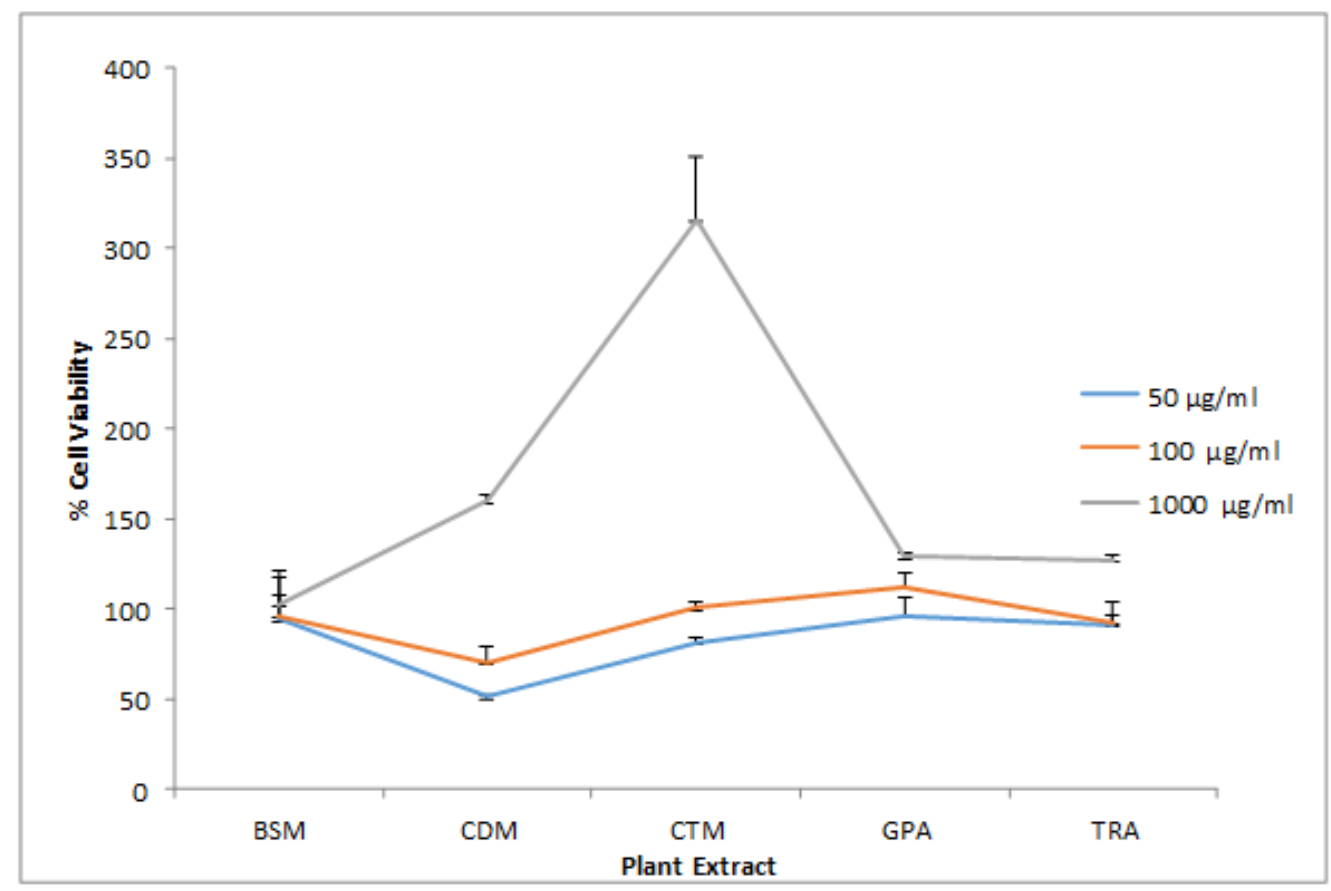

Figure 2: Cell viability of the active plant extracts of $B$. saligna (BSM), C. tormentosa (CTM, methanol extract), C. dimidiatus (CDM, methoanol extract), G. perpensa (GPA, aqueous extract) and T. riparia (TRA, aqueous extract) on the BALB/C monocyte macrophage cell line (J774.2). Data represented as mean $\pm \operatorname{SD}(n=3)$. 


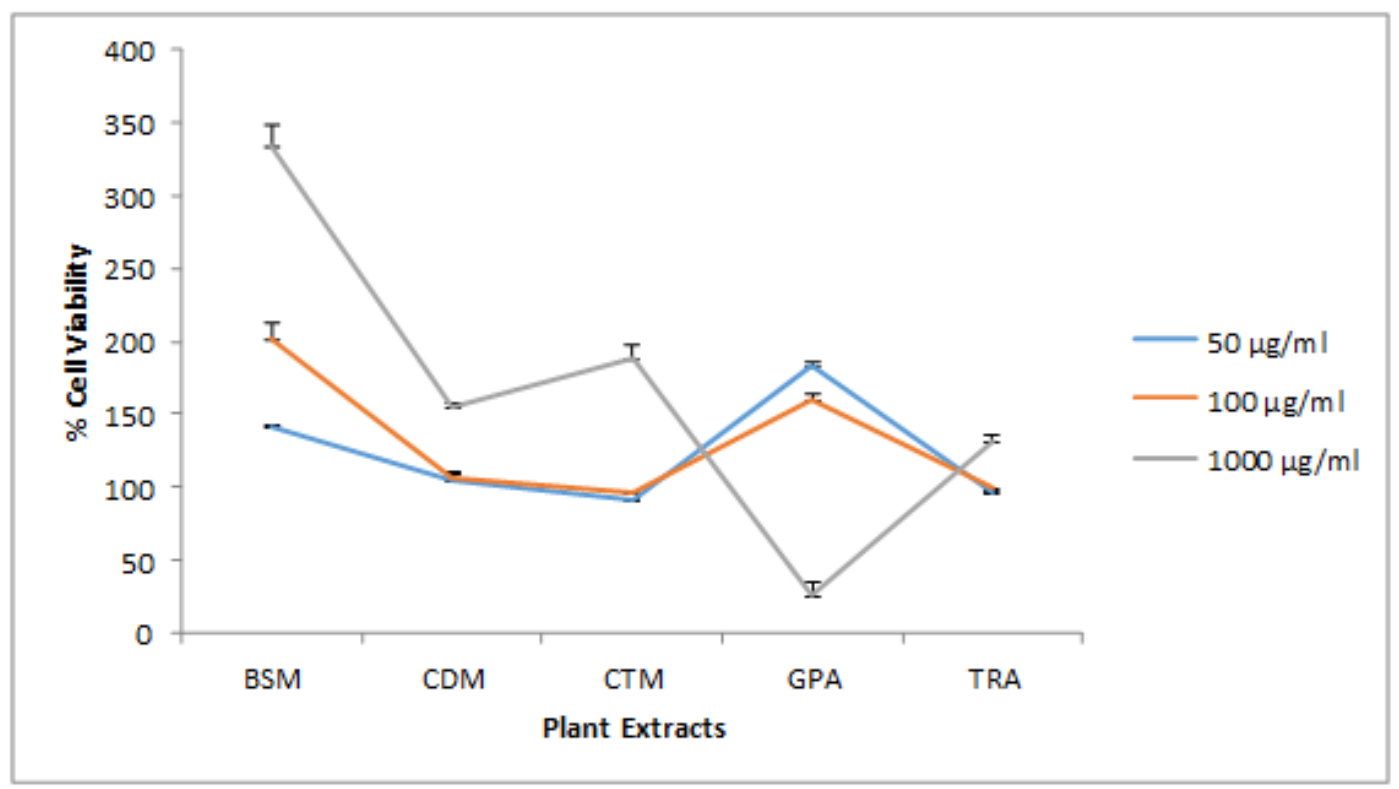

Figure 3: Cell viability of the active plant extracts of $B$. saligna (BSM), C. tormentosa (CTM, methanol extract), C. dimidiatus (CDM, methoanol extract), G. perpensa (GPA, aqueous extract) and T. riparia (TRA, aqueous extract) on the peripheral blood mononucleated cell line (PBMC). Data represented as mean $\pm \mathrm{SD}(n=3)$.

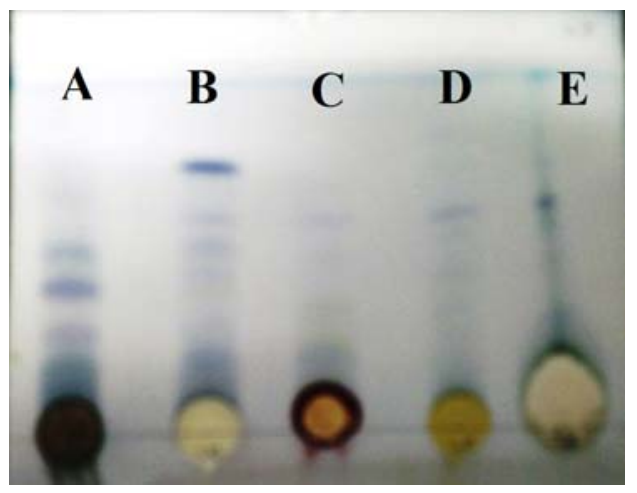

Figure 4: TLC of the methanol extracts of $(A) B$. saligna, (B) C. dimidiatus, (C) C. tomentosa, aqueous extracts of (D) G. perpensa, and (E) T. riparia leaves using Hexane : Ethyl Acetate (7:3) as a mobile phase and developed with vanillin spray reagent for visualization. In the bioautography qualitative analysis, only the methanol extracts of $B$. saligna and $C$. dimidiatus demonstrated inhibition of growth of $M$. smegmatis on the bioautogram as they both showed two clear bands (Figure 5).

\section{DISCUSSION}

From a literature survey carried out on the medicinal plants for the treatment of TB in South Africa, a total of nine plants were selected according to their traditional use in treatment of various ailments including cough, bronchitis, chest complaints, pneumonia and TB in the

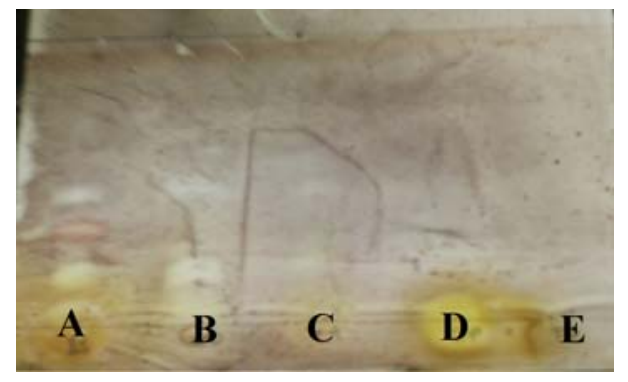

Figure 5: Bioautograph of the methanol extracts of (A) B. saligna, (B) C. dimidiatus, (C) C. tomentosa, aqueous extracts of (D) G. perpensa, and (E) T. riparia leaves using Hexane Ethyl Acetate (7:3) as a mobile phase. Clear zones denote a compound of interest

present study [3, 14, 15, 32, 33]. This study has revealed that the methanol extracts of $B$. saligna, C. tormentosa and C. dimidiatus; and aqueous extracts of $G$. perpensa and $T$. riparia possesses significant activity against $M$. smegmatis, $M$. tuberculosis H37Rv (ATCC 25177) and the three well-characterized clinical isolates of MDR and XDR-TB. Other than a high concentration of G. perpensa, none of these extracts demonstrated any toxic or cytotoxic activity.

Although the remaining four plant species $(D$. cinerea, E. capensis, F. sur and $L$. leonurus) have been reported to be used in the treatment of TB and related diseases [13, 16, 18], they failed to display any activity against the screened 
strains in our assays. The possible explanation could be that the antimycobacterial effect of these plants is mediated through immunostimulation or immunomodulation rather than direct inhibition of mycobacterial growth; or that the potential active compounds need to be metabolically activated in vivo by specific enzymes or may have a $\mathrm{pH}$ dependant biological activity [37]. The extracts might also contain little of the active ingredient [38]. Cell wall biosynthesis is a key target for antimycobacterial chemotherapy. Due to the complex lipoglycan calyx on the cell surface, which provide a significant physical barrier to intracellular acting compounds [39], many antibiotics do not work on M. tuberculosis [40]. This could explain the lack of activity shown by some of the plant extracts against MTB in this study. Therefore, the negative results obtained could not preclude the potential antimycobacterial effect of those medicinal plants.

There has been an earlier report that acetone/water (4:1) crude extract of $B$. saligna [3] and ethanol extract of $C$. tomentosa [2] exhibit significant activity against Mycobacterium aurum. While Springfield and Weitz [36] found that some extracts of the leaves of Carpobrotus mellei exhibited inhibition against $M$. smegmatis, Lall and Meyer [13] reported that G. perpensa and $T$. riparia did not show any positive antimycobacterial activity against $M$. tuberculosis even which is contradictory to our study. Although the methanol extracts of $B$. saligna and C. dimidiatus demonstrated inhibition of growth of $M$. smegmatis on the bioautograph, the antimycobacterial activity of the other plant extracts could not be scientifically validated by bioautography. The lack of correlation between the MIC values obtained and bioautography bands can be attributed to the vaporization of volatile active compounds during removal of the TLC eluents or interference of synergism between the active constituents by TLC separation as previously suggested [29].

\section{CONCLUSION}

The findings in this study validate the use of the five plant species currently used in for treatment of TB and other respiratory diseases for their antimycobacterial activity. Further isolation, characterization and identification of the bioactive compounds responsible from these plants are required. Using safe medicinal plants for the treatment of TB offers a great hope to fulfill these needs because of their chemical diversity.

\section{DECLARATIONS}

\section{Acknowledgement}

None provided

\section{Conflict of interest}

No conflict of interest is associated with this work.

\section{Contribution of authors}

We declare that this work was done by the authors named in this article and all liabilities pertaining to claims relating to the content of this article will be borne by the authors.

\section{Open Access}

This is an Open Access article that uses a funding model which does not charge readers or their institutions for access and distributed under the terms of the Creative Commons Attribution License (http://creativecommons.org/licenses/by/ 4.0) and the Budapest Open Access Initiative (http://www.budapestopenaccessinitiative.org/rea d), which permit unrestricted use, distribution, and reproduction in any medium, provided the original work is properly credited.

\section{REFERENCES}

1. WHO. Global tuberculosis report 2013. Geneva 2013.

2. Luo X, Pires D, Aínsa JA, Gracia B, Mulhovo S, Duarte A, Anes E, Ferreira MJ. Antimycobacterial evaluation and preliminary phytochemical investigation of selected medicinal plants traditionally used in Mozambique. J Ethnopharmacol 2011;137: 114-120.

3. Bamuambaa K, Gammonb, David W., Meyers P, DijouxFranca M-G, Scott G. Anti-mycobacterial activity of five plant species used as traditional medicines in the Western Cape Province (South Africa). J Ethnopharmacol 2008;117:385-390.

4. Samie A, Obi CL, Bessong PO, Lall N. Activity profiles of fourteen selected medicinal plants from Rural Venda communities in South Africa against fifteen clinical bacterial species. Afr J Biotechnol 2005;4:14431451.

5. Ndip RN, Malange Tarkang AE, Mbullah SM, Luma HN, Malongue A, Ndip LM, Nyongbela K, Wirmum $C$, Efange SM. In vitro anti-Helicobacter pylori activity of selected medicinal plants from North West Cameroon. J Ethnopharmacol 2007;114:452-457.

6. Copp BR, Pearce AN. Natural product growth inhibitors of Mycobacterium tuberculosis. Nat Prod Rep 2007; 24:278-297.

7. Heinrich M., Gibbons S. Ethnopharmacology in drug 3. discovery: an analysis of its role and potential contribution. J Phar Pharmacol 2001;53:425-432.

8. Cunningham $A B$. Development of a conservation policy on commercially exploited medicinal plants. A case study from Southern Africa. In: Akarele O, Heywood, $V$. and Synge $H$., ed. The conservation of medicinal plants. Cambridge: Cambridge University Press; 
1991.

9. Mmushi T, Masoko P, Mdee L, Mokgotho M, Mampuru L, Howard R. Antimycobacterial evaluation of fifteen medicinal plants in South Africa. African Journal of Traditional Complimentary and Alternative Medicine. 2010;7(1):34-39.

10. Gur S, Turgut-Balik D, Gur N. Antimicrobial activities and some fatty acids of turmeric, ginger root and linseed used in the treatment of infectious diseases. J Agr Sci 2006;2:4.

11. Mativandlela SPN, Meyer JJM, Hussein AA, Houghton $P J$, Hamilton CJ, Lall $N$. Activity against Mycobacterium smegmatis and $M$. tuberculosis by extracts of South African medicinal plants. Phytother Res 2008;22:841- 845.

12. Thring TSA, Springfield EP, Weitz FM. Antimicrobial activities of four plant species from the Southern Overberg region of South Africa. Afr $J$ Biotech 2007;6:1779- 1784.

13. Lall N, Meyer JJM. In vitro inhibition of drug-resistant and drug-sensitive strains of Mycobacterium tuberculosis by ethnobotanically selected South African plants. J Ethnopharmacol 1999;66:347-354.

14. Scott GA, Springfield EP, Coldrey N. A pharmacognostical study of 26 South African plant species used as traditional medicines. Pharm Biol 2004;42:186-213.

15. Springfield EP, Amabeoku G, Weitz F, Mabusela W, Jhonson Q. An assessement of two Carpobrotus species extracts as potential antimicrobial agents. Phytomedicine. 2003;10(5):434-439.

16. Vogt $K$. A field guide to the identification, propagation and uses of common trees and shrubs of dryland Sudan. United Kingdom: SOS Sahel International; 1995.

17. Hutchings A, Van Staden J. Plants used for stress-related ailments in traditional Zulu, Xhosa and Sotho medicine Part I. Plants used for headaches. J Ethnopharmacol 1994;43:89-124.

18. Hutchings A. Zulu medicinal plants. Pietermaritzburg: Natal University Press; 1996.

19. Eloff JN. A Sensitive and quick Microplate Method to determine the Minimum Inhibitory Sensitive and Concentration of Plant Extracts for Bacteria Planta Medica 1998;64:711-713.

20. Meyer BN, Ferrign RN, Putnam JE, Jacobson LB, Nicholas DE, McLaughlin JL. Brine Shrimp: $A$ Convenient General Bioassay for Active Plant Constituents. Planta Medica 1982;45:31-34.

21. Boyum A. Isolation of mononuclear cells and granulocytes from human blood. Scand J Clin Lab Invest 21 Suppl 1968;97:77-89.

22. Patterson MK. Measurement of growth and viability of cells in culture. Methods Enzymol 1979;58(141).

23. Mosmann T. Rapid colorimetric assay for cellular growth and survival: Application to proliferation and cytotoxicity assays. J Immunol Meth 1983;65(1-2):5563.

24. Amarowicz R, Maryniak A, Shahidi F. TLC Separation of methylated Epigallocatechin -3-Gallate. Czech J Food
Sci 2005;23(1):36-39.

25. Carr JD, Rogers CB. Chemosystematic studies of the genus Combretum [Combretaceae], I. A convenient method of identifying species of this genus by a comparison of the polar constituents extracted from leaf material. S Afr J Bot 1987;53(1):173-176.

26. Begue WJ, Kline RM. The use of tetrazolium salts in bioauthographic procedures. $J$ Chromat $A$ 1972;64(1):182-184.

27. Dalton T, Cegielski P, Akksilp S, Asencios L, Campos Caoili J, Cho SN, et al. Prevalence of and risk factors for resistance to second-line drugs in people with multidrug-resistant tuberculosis in eight countries: A prospective cohort study. The Lancet. 2012;380(9851):1406-1417.

28. WHO. WHO Global Task Force outlines measures to combat XDR-TB worldwide 2006.

29. Masoko $P$, Eloff JN. Bioautography indicates the multiplicity of antifungal compounds from twenty-four southern African Combretum species (Combretaceae). A J Biotechnol 2006;5(18):16251647.

30. Masoko P, Nxumalo KM. Validation of Antimycobacterial Plants Used by Traditional Healers in Three Districts of the Limpopo Province (South Africa). J Evid Based Complementary Altern Med 2013;2013:1-7.

31. Masoko P, Mmushi TJ, Mogashoa MM, Mokgotho MP, Mampuru LJ, Howard RL. In vitro evaluation of the antifungal activity of Sclerocarya birrea extracts against pathogenic yeasts. Afr $\mathrm{J}$ Biotechnol 2008;7:3521-3526.

32. McGaw LJ, Lall N, Meyer JJM, Eloff JN. The potential of South African plants against Mycobacterium infections. J Ethnopharmacol 119. 2008;119:482-500.

33. Van Wyk B, Gericke N. Peoples Plants -A guide to useful plants of South Africa Pretoria: Briza Publications; 2003.

34. King G. Uptake of carbon monoxide and hydrogen at environmentally relevant concentrations by mycobacteria. Appl Environ Microbiol 2003;69:72667272.

35. Pauli GF, Case RJ, Inui T, Wang Y, Cho S, Fisher NH, Franzblau SG. New perspectives on natural products in TB drug research. Life Sci 2005;78:485-494.

36. Springfield EP, Weitz F. The scientific merit of Carpobrotus mellei L. based on antimicrobial activity and chemical profiling. Afr J Biotechnol 2006;5:12891293.

37. RIos JL, Recio MC. Medicinal plants and antimicrobial activity. J Ethnopharmacol. 2005;100(1-2):80-84.

38. Apak L, Olila D. The in-vitro antibacterial activity of Annona senegalensis, Securidata longepediculata and Steganotaenia araliacea-Ugandan medicinal plants. Afr Health Sci 2006;6:31-35.

39. Ballell L, Field RA, Duncan K, Young RJ. New smallmolecule synthetic antimycobacterials. Antimicrob Agents Chemother 2005;49:2153-2163.. 